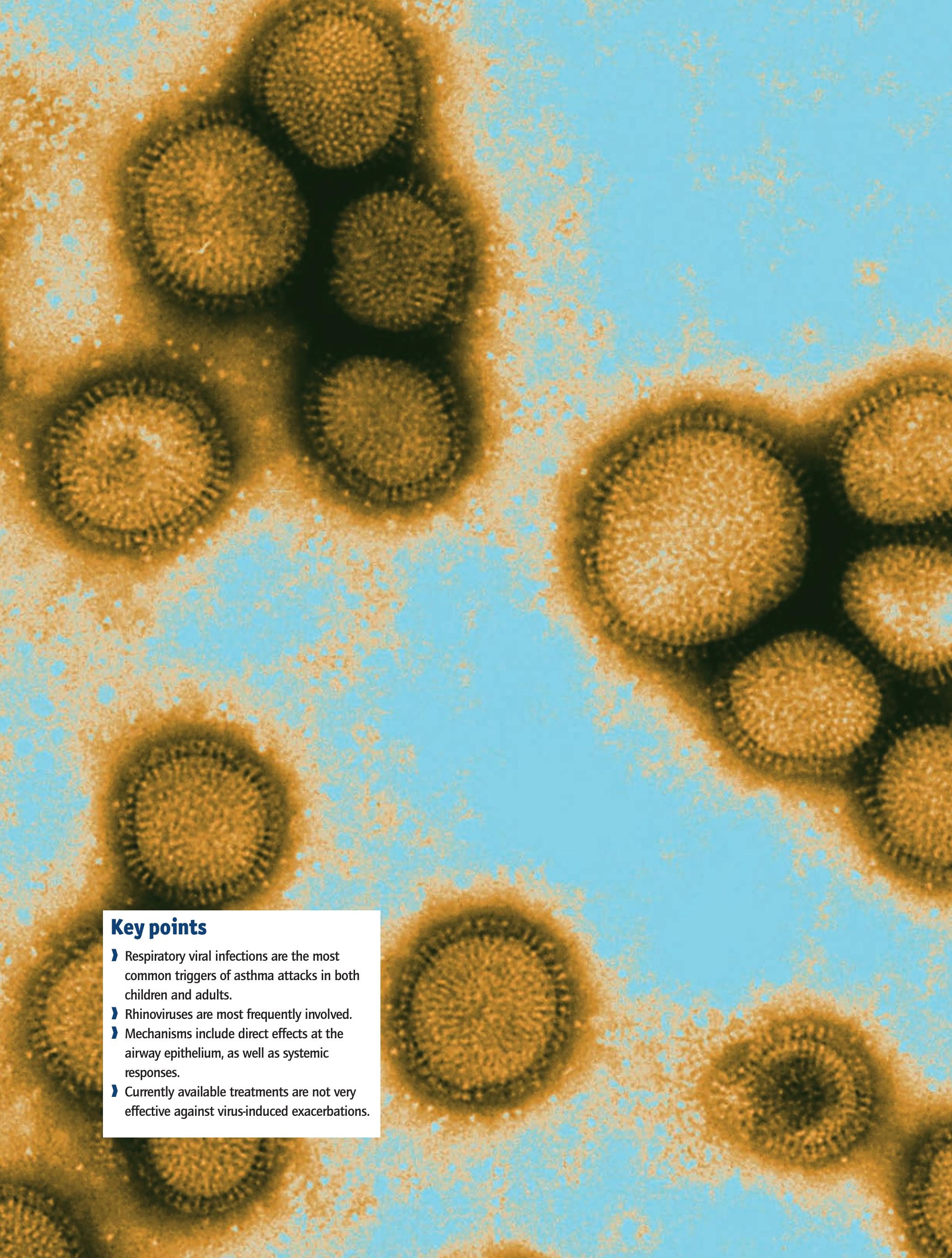




\section{Viruses and asthma exacerbations}

\section{Educational aims}

1 To emphasise that respiratory viruses are major triggers of acute asthma exacerbations in both children and adults.

1 To describe the current understanding of underlying mechanisms.

I To discuss possibilities for intervention.

\section{Summary}

Acute exacerbations of asthma are the major cause of morbidity and mortality of the disease, and one of the most difficult outcomes to prevent and treat. Respiratory viral infections cause $>80 \%$ of asthma exacerbations in children and $>50 \%$ in adults. In recent years, an increasing number of studies have investigated the mechanisms underlying asthma exacerbations; however, our understanding is still incomplete. Promising new data suggest the possibility for novel prevention and/or therapeutic strategies. This review aims to increase understanding of the epidemiology, mechanisms and potential treatments for virus-induced asthma exacerbations.

All patients with asthma are at risk of having exacerbations. Exacerbations are a major cause of morbidity and mortality, and are associated with high costs, including time lost at school and work, primary care consultations and hospital admission. Such risk is only partially affected by the optimisation of treatment with inhaled glucocorticosteroids and long-acting $\beta_{2}$-agonists, suggesting that the pathogenesis of asthma exacerbations and that of persistent asthma are likely to be different.

\section{Triggers of asthma exacerbations}

The observation that common colds in asthmatic individuals very frequently lead to acute asthma exacerbations has been consistently observed in clinical practice. Viral identification was first achieved $>30$ years ago using culture and serology. However, these methods have low sensitivity, especially for rhinoviruses (RV) and corona viruses, thus underestimating the impact of viral infection on acute wheezing.

This problem was solved with the development of molecular diagnostic tools, such as PCR (figure 1). At present, these methods are mostly available for research purposes, but are steadily becoming more widely used and standardised.

The use of PCR-based techniques and prospective study designs were critical for the accurate description of the role of viral infections in asthma exacerbations. In the mid-1990s, the proportion of exacerbations associated with an upper respiratory tract viral infection was $85 \%$ in children and $44 \%$ in adults $[1,2]$. More recent studies have confirmed and provided more information about these data. In children visiting the emergency
The ERS designates this

educational activity for a

maximum of 1 CME credit. For

information on how to earn

CME credits, see page 106.

A. Bossios ${ }^{1}$

N.G. Papadopoulos²

${ }^{1}$ Lung Pharmacology Group, Dept of Internal Medicine/ Respiratory and Allergology, Göteborg University, Gothenburg, Sweden. ${ }^{2}$ Allergy Dept, 2nd Pediatric Clinic, University of Athens, Athens, Greece.

\section{Correspondence: \\ N.G. Papadopoulos \\ 41, Fidippidou Str \\ 11527 Goudi \\ Athens}

Greece

Fax: 302107726290

E-mail:ngp@allergy.gr

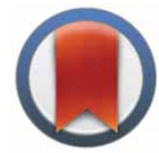

CrossMark

$\leftarrow$ click for updates 


\section{Figure 1}

Amplicons from $P C R$ for $R V$, adenovirus ( $A D)$, parainfluenza (PIV)-1, RSV and corona (OC) performed on a nasal lavage sampled from an infant hospitalised for acute bronchiolitis.

\section{Figure 2}

Viral agents implicated in acute asthma exacerbations in school children and adults, as a percentage of total isolated viruses. Rhinovirus and corona viruses represent $80-90 \%$ of cases. Adapted with permission from [7].

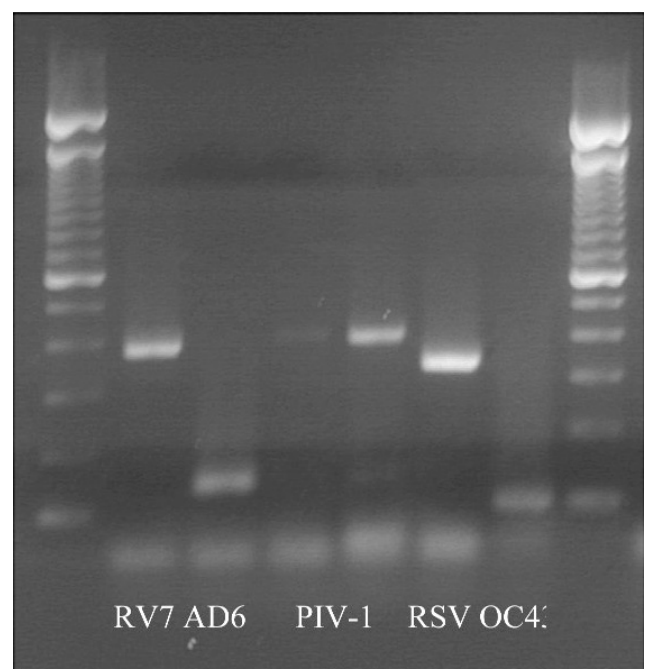

room for an asthma exacerbation, respiratory viruses were detected in $82 \%$ of infants and $83 \%$ of older children [3]. A similar detection rate $(82 \%)$ was found in children hospitalised with severe exacerbations [4]. In inner-city asthmatic adults, virus was detected in $44 \%$ of followed-up subjects and up to $55 \%$ of subjects presenting to the emergency department [5]. However, in a more recent study, where PCR was applied for all common respiratory viruses, the detection rate reached $76 \%$ [6].

Therefore, it was confirmed that respiratory viruses are very common triggers of asthma attacks, and are present in the vast majority of instances.

\section{Agents involved in acute episodes of wheeze}

The most commonly involved viruses are RVs, respiratory syncytial virus (RSV), influenza and parainfluenza viruses, corona viruses, enterovirus and adenovirus (figure 2).

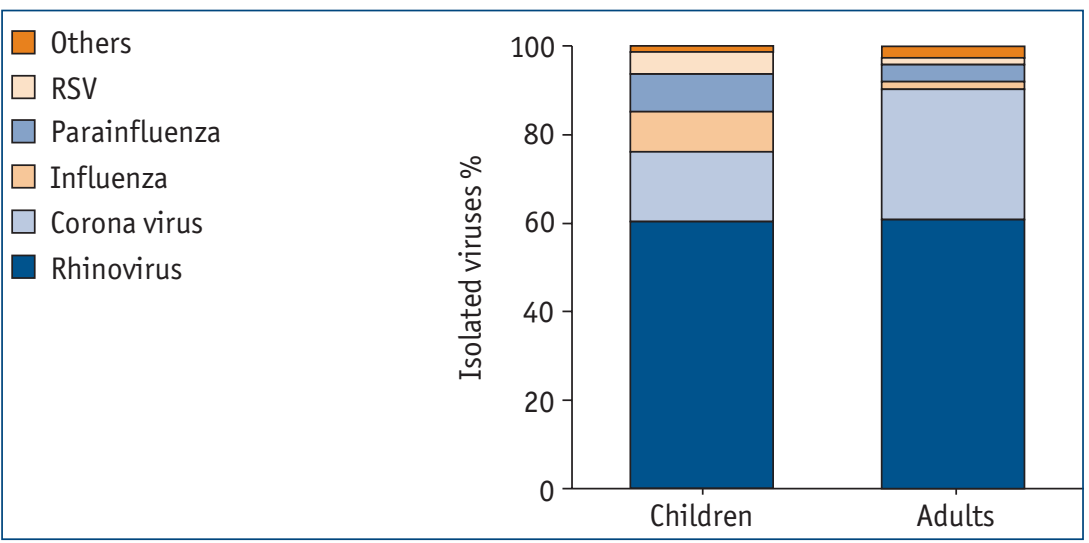

RSV is the most commonly identified agent in acute bronchiolitis in infancy, which is frequently indistinguishable from the first acute exacerbation of asthma [8]. Later on in life, RSV usually produces only non-complicated upper airways infections, but serious RSV infections can become a problem in the elderly. It is still unclear whether RSV may be a direct cause of asthma, or if it affects only genetically predisposed subjects.

$\mathrm{RV}$ is the most dominant virus, probably at all ages and certainly after infancy, representing up to two thirds of upper respiratory infections. They are also associated with $~ 50 \%$ of all asthma exacerbations in studies of asthmatic children [9].

RVs are small RNA viruses belonging to the family Picornaviridae, which also includes enteroviruses, cardioviruses and apthoviruses. There are >100 serotypes. They are nonenveloped viruses with an icosahedral (20-sided) shape and they are $\sim 25 \mathrm{~nm}$ in diameter. They are divided into two different types: major $(90 \%)$, which bind to intercellular adhesion molecule (ICAM)-1; and minor (10\%), which bind to the low-density lipoprotein receptor [10].

Influenza and parainfluenza viruses affect all age groups, and they represent an important pathogen during winter [11]. Corona viruses are frequent agents in common colds, as well as adenoviruses. Mycoplasma and Chlamydia pneumoniae are also among the agents isolated in both colds and asthma exacerbations, although the relative proportion varies considerably between studies.

In the last few years, new respiratory viruses have been identified that are potential asthma exacerbation precipitants. Human metapneumonovirus (hMPV) was detected in up to $7 \%$ of adults hospitalised for an acute asthma exacerbation [12]. hMPV is a recently discovered paramyxovirus that has been classified in the genus Metapneumovirus and the subfamily Pneumovirinae. The epidemiological profile and clinical manifestations of hMPV infection are similar to RSV, as hMPV was detected in up to $16 \%$ of infants hospitalised for acute bronchiolitis in a previous study [13].

Torqueteno virus (TTV), a single-stranded circular DNA virus, was originally identified in 1997 and classified in a new genus, Anellovirus. A recent study detected an increased amount in children with mild-to-moderate asthma in comparison with healthy controls, with a correlation between nasal TTV load and airway resistance [14]. 


\section{Mechanisms of virus- induced acute asthma exacerbations}

Respiratory viruses may induce asthma exacerbations though direct effects on their main target, i.e. the airway epithelium, as well as via a systemic immune reaction. Additional mechanisms, such as neural reflexes or physiological disturbances (mouth breathing, reduced mucociliary clearance), have been proposed but not yet adequately studied.

\section{Epithelial effects}

\section{Viral replication in the bronchial epithelium}

Most respiratory viruses are able to replicate in both the upper and lower respiratory epithelium, thus inducing cytotoxicity. The ability of RVs to infect and replicate in the lower airway has been questioned in the past, based on temperature preferences. It was shown, however, that RVs are able to replicate at a lower airway temperature [15] and to infect human bronchial epithelial cells [16]. Replication characteristics are not different from those reported for nasal and tracheal epithelium, suggesting that the whole respiratory tree may be equally susceptible to RV. Using human volunteers who were subjected to an experimental RV upper respiratory infection, the current authors were able to detect both genomic and replicative strand viral RNA using in situ hybridisation in the bronchial biopsies of $50 \%$ of infected subjects [16], indicating that RVs not only reach and enter the bronchial epithelium after upper airway infection but also replicate in it (figure 3). These results were confirmed in a recent study using multiple mucosal biopsy samples and cell brushings, and immunohistochemistry with specific monoclonal antibodies against RV16, which demonstrated a patchy distribution of infected cells [17].

\section{Viral infection induces epithelial inflammation}

When a virus reaches and infects the bronchial epithelium, it may upregulate the expression of a range of pro-inflammatory mediators (table 1). The pro-inflammatory cytokine interleukin (IL)-1 $\beta$ was detected in nasal secretions of experimentally infected volunteers. IL-8, a key mediator in
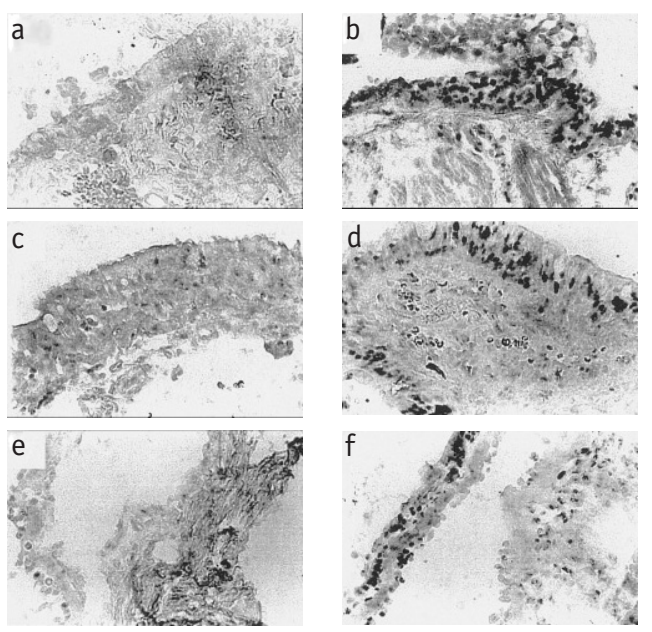

Figure 3

In situ hybridisation for rhinovirus RV16 in sections of human bronchial biopsy samples. Negative bronchial biopsy samples taken before infection from subjects $(a, c$ and $e$ ) are compared with RV16-positive biopsy samples from the respective subjects obtained during experimental $R V 16$ infection ( $b, d$ and f). The hybridisation signal for RV16 is visible in the cells (black) and is localised mainly on epithelium. Adapted with permission from [16]. neutrophil-mediated acute inflammation, was also detected in naturally occurring infections correlating with neutrophilia in blood and nasal samples in children with virally precipitated asthma or experimental infection [18].

Epithelial neutrophil-activating peptide (ENAP)-78, which also induces neutrophil migration, was found to be elevated in nasal samples from RV-infected subjects [19]. Other RV-induced mediators include eotaxin and RANTES (regulated on activation, T-cell expressed and secreted), potent eosinophil chemoattractants, and IL-16 and monocyte chemoattractant protein (MCP)-1 chemoattractants for CD4 T-lymphocytes and natural killer cells, respectively.

\section{Table 1 Mediators released from epithelial cells after RV infection}

\begin{tabular}{|c|c|c|}
\hline $\begin{array}{l}\text { Pro-inflammatory } \\
\text { mediator release }\end{array}$ & $R V$ serotype & $\begin{array}{l}\text { Bronchial epithelial cells } \\
\text { used }\end{array}$ \\
\hline ENAP-78 & 39 & BEAS-2B \\
\hline Eotaxin & $1 b, 16$ & $B E A S-2 B$ \\
\hline Eotaxin-2 & $1 b, 16$ & $B E A S-2 B$ \\
\hline FGF-2 & $1 b, 16$ & $B E A S-2 B$ \\
\hline G-CSF & 39 & $B E A S-2 B$ \\
\hline GM-CSF & $2,14,16,39,49$ & $B E A S-2 B$ \\
\hline GRO- $a$ & 39 & $B E A S-2 B$ \\
\hline IL-1 $\beta$ & 39 & $B E A S-2 B$ \\
\hline IL-6 & $1 A, 2,7,14,16,39$ & $B E A S-2 B$ \\
\hline \multirow[t]{2}{*}{ IL-8/CXCL8 } & $16,2,7,9,14,16,3$ & $B E A S-2 B$ \\
\hline & 9,49 & $M R C-5$ \\
\hline$I L-11$ & 14 & A549, MRC-5 \\
\hline$I L-16$ & 2,7 & HBEC \\
\hline MIP-1 & $1 b, 16$ & $B E A S-2 B$ \\
\hline RANTES & $1 b, 2,7,16,49$ & $B E A S-2 B, H B E C, A 549$ \\
\hline$F G F-2$ & $1 b$ & $B E A S-2 B$ \\
\hline VEGF & $1 b$ & $B E A S-2 B, H B E C$ \\
\hline
\end{tabular}




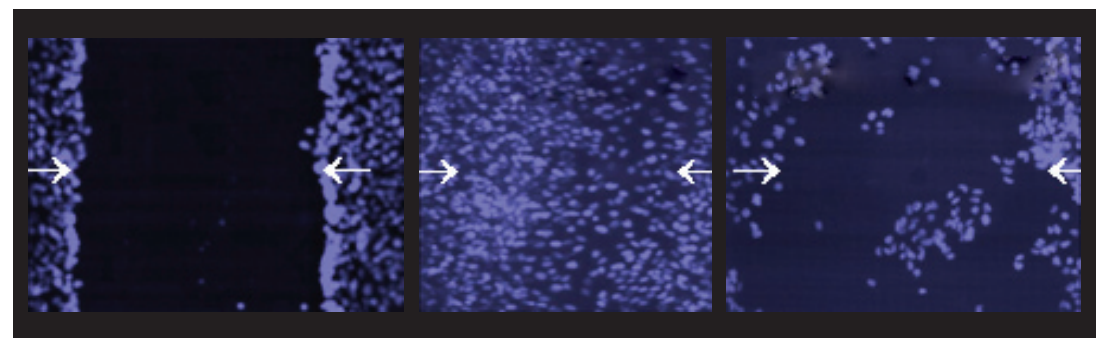

Figure 4

$B E A S-2 B$ cells were mechanically damaged following $R V$, with or without infection. Cells were stained with the DNA dye DAPI, and taken at baseline and after 24 hours. There is defective healing in $R V$-infected cells. Adapted with permission from [24].

Interestingly, it has recently been shown that RV infection may stimulate the epithelial production of fibroproliferative and angiogenic factors, such as fibroblast growth factor (FCF)-2 and vascular endothelial growth factor (VEGF) [20], suggesting a pathway that may contribute to the structural changes (remodelling) seen in asthma.
Parainfluenza viruses also induce epithelial inflammation, leading to epithelial damage and influx of inflammatory cells. They can also cause bronchial hyperresponsiveness and bronchial fibrosis through the induction of transforming growth factor $\beta$, possibly contributing to the pathological structural changes in asthma [21].

Influenza viruses infect airway epithelial cells, leading to enhanced inflammation, cell death, as well as the release of pro-inflammatory mediators and chemokines RANTES, MCP-1 and IL-8 [22].

$\mathrm{RV}$ is also able to induce the upregulation of ICAM-1, its own receptor [23]. ICAM-1 plays a major role in leukocyte recruitment and allergic inflammation, as well as vascular cell adhesion molecule (VCAM), which is also induced.

Most of the above mediators, including IL-8, IL-6, CXCL10, ICAM-1 and VCAM, are transcriptionally regulated by nuclear factor (NF)- $\kappa \mathrm{B}$.

\section{RV induces cytotoxicity and apoptosis in bronchial epithelium}

It has been generally accepted that RVs do not induce cytotoxicity in vitro or in vivo. However, two recent studies that were designed to assess the ability of RVs to infect primary human bronchial epithelial cells have unexpectedly observed RV-associated cytotoxicity [16]. Further investigating this phenomenon in an in vitro BEAS-2B cell line system, it was shown that RVs can become cytotoxic, depending upon serotype, dose and especially confluence of the cultured epithelium [24], suggesting that RVs can adopt this property in a damaged epithelium.
Furthermore, RV may delay wound healing (figure 4), possibly through a defect in the proliferative capacity of epithelial cells. Another recent study has also shown that RV14 can induce epithelial cell death via mitochondrial pathway-induced apoptosis [25].

Apoptosis is an essential physiological mechanism used by the epithelium as self-defence against virally infected cells. This mechanism seems to be defective in bronchial epithelial cells from asthmatic individuals; when infected with $R V$, the cells displayed profoundly impaired apoptosis mediated through interferon (IFN)- $\beta$, resulting in increased virus replication [26]. It has also been proposed that infection with $C$. pneumoniae may inhibit epithelial cell apoptosis, thus enhancing infected cell and pathogen survival [27]. Although this article is focused on viral infection, increasing evidence suggests a role for atypical bacterial (C. pneumoniae and $M$. pneumoniae) in both chronic-stable and acute exacerbations of asthma [28].

\section{Systemic effects}

In a simplified model, asthma is characterised by a T-helper cell (Th)1/Th2 imbalance, with a Th2 preponderance. IFN- $\gamma$ is the central cytokine in type I, as opposed to IL-4 and IL-5 in type II responses. It seems contradictory that a viral infection, which is mainly IFN inducing, may exacerbate a Th2 disease. However, it appears that Th1/Th2 cytokine imbalance affects the way a host responds to viral infection. An inverse correlation between RV persistence after experimental infection, as well as symptom score, and the ratio IFN- $\gamma /$ IL-5 levels in nasal secretions has been reported [18]. When peripheral blood mononuclear cells (PBMCs) from normal or atopic asthmatic subjects were exposed to RVs, time- and dose-dependent increases of IFN- $\gamma$, IL12 and IL-10 were observed in both groups [29]. IL-4 was induced only in the asthmatic group, which produced significantly lower levels of IFN- $\gamma$ and IL-12, and higher levels of IL-10. Until recently, it was not certain whether RVs can actually reach the bloodstream. However, it has recently been shown that RV viraemia occurs frequently after a cold, although it only lasts for a short period of time and is more frequent in cases where an acute asthma exacerbation occurs [30].

During RV experimental infection, an increase in submucosal lymphocytes and eosinophils has been observed; in the case of 
asthmatic subjects, only the latter persisted into convalescence [31]. When PBMCs from normal and atopic asthmatic individuals are exposed to $\mathrm{RV}$, there are no differences in T- or B-cell proportions, whereas CD14+ monocytes are reduced [32]. An increase in cell activation (CD25+ upregulation) and induction of the costimulatory machinery are observed. B7-1 (CD80) was upregulated on monocytes and B7-2 (CD86) on B-cells, and this was suboptimal in the asthmatic population. Interestingly, these costimulatory molecules were downregulated in the peripheral blood of atopic asthmatic children during an acute exacerbation, a finding that has been attributed to possible migration of activated cells in the lung [33].

\section{Viral infection induces long-lasting airway hyperresponsiveness}

Airway hyperresponsiveness (AHR) is associated with the pathogenesis of asthma. Several studies have shown increased AHR after respiratory infections. Human experimental infections with RV increased AHR to non-specific stimuli for up to 4 weeks after a viral infection in allergic subjects [34]. More recently, a cohort of children with post-viral asthma was prospectively followed-up and AHR was assessed at regular intervals after a cold. The majority of documented infections were due to RV (82\%). The duration of post-viral AHR is actually much longer, $\sim 7$ weeks when no subsequent cold occurs, but because of recurrent colds it frequently continues for several months. Atopic subjects had an increased number of colds and, therefore, significantly prolonged duration of AHR [35].

\section{Synergy between viral infections and other environmental factors}

Epidemiological studies suggest a synergy between viral infections and other environmental factors in the induction of exacerbations.

Green et al. [36] have reported that the risk of admission to hospital with acute asthma in adults was clearly increased with the combination of sensitisation and current exposure to high levels of sensitising allergens and the presence of a viral infection. In human experimental RV infection models, it has been shown that there is an augmentation of allergeninduced effects after viral infection [37]. When the current authors exposed bronchial epithelial cells to RV and Der p I (the major allergen of house dust mite), a synergistic effect in the induction of IL-8 and ICAM-1 was observed. However, other studies have failed to demonstrate synergy [38], possibly due to differences in exposure characteristics.

Exposure to $\mathrm{NO}_{2}$ in the week before the start of a respiratory viral infection has been associated with an increased severity of asthma exacerbation [39]. In vitro, epithelial cells exposed to $\mathrm{RV}$ and $\mathrm{NO}_{2}$ resulted in a synergistic increase in both IL-8 release and ICAM-1 expression [40].

\section{Antiviral strategies for the prevention and treatment of virus- induced asthma exacerbations}

Whether a window of opportunity exists from the occurrence of a viral upper respiratory infection until the development of an acute asthma exacerbation, during which an antiviral strategy may be effective, is not known. Alternatively, it cannot be predicted whether immunisation against one or more of the viruses involved will be able to reduce virus-associated asthma episodes or just shift the problem to different strains. In order to answer the above questions, reliable antiviral tools are required. Unfortunately, the only virus for which there is reliable prevention (and an effective vaccine) is influenza. Of course, the effectiveness of the vaccine varies every year and does not apply to pandemic strains. Conversely, RVs represent the majority of virus-induced asthma exacerbations cases, for which the treatment options remain unsatisfactory. RV has $>100$ serotypes, making it impossible to develop an effective vaccine. Vaccines for other respiratory viruses are either in development, are not sought after or are impractical.

A variety of antiviral agents against $R V$ s have been studied. Additional antiviral/anti-inflammatory strategies against the common cold have been suggested with varying but usually little success (table 2) [41].

Antiviral strategies include the regularly used, but with small therapeutic value, ascorbic acid, zinc and echinacea. Local IFN- $\alpha$ therapy
Educational questions

1. Which of the following causes the highest proportion of asthma exacerbations:
a) Allergen exposure.
b) Viral infections.
c) Pollutants.
d) Stress.

2. Put into sequence the events that take place in the airways, leading from exposure to virus to an acute asthma attack.
a) Mediator production.
b) Epithelial infection.
c) Oedema and bron- choconstriction.
d) Cellular infiltration.
e) Virus replication.

3. Which of the following treatments have been shown to have a moderate benefit in preventing virus-induced asthma exacerbations (true or false)?
a) Ascorbic acid.
b) Macrolide antibiotics.
c) Corticosteroids. 


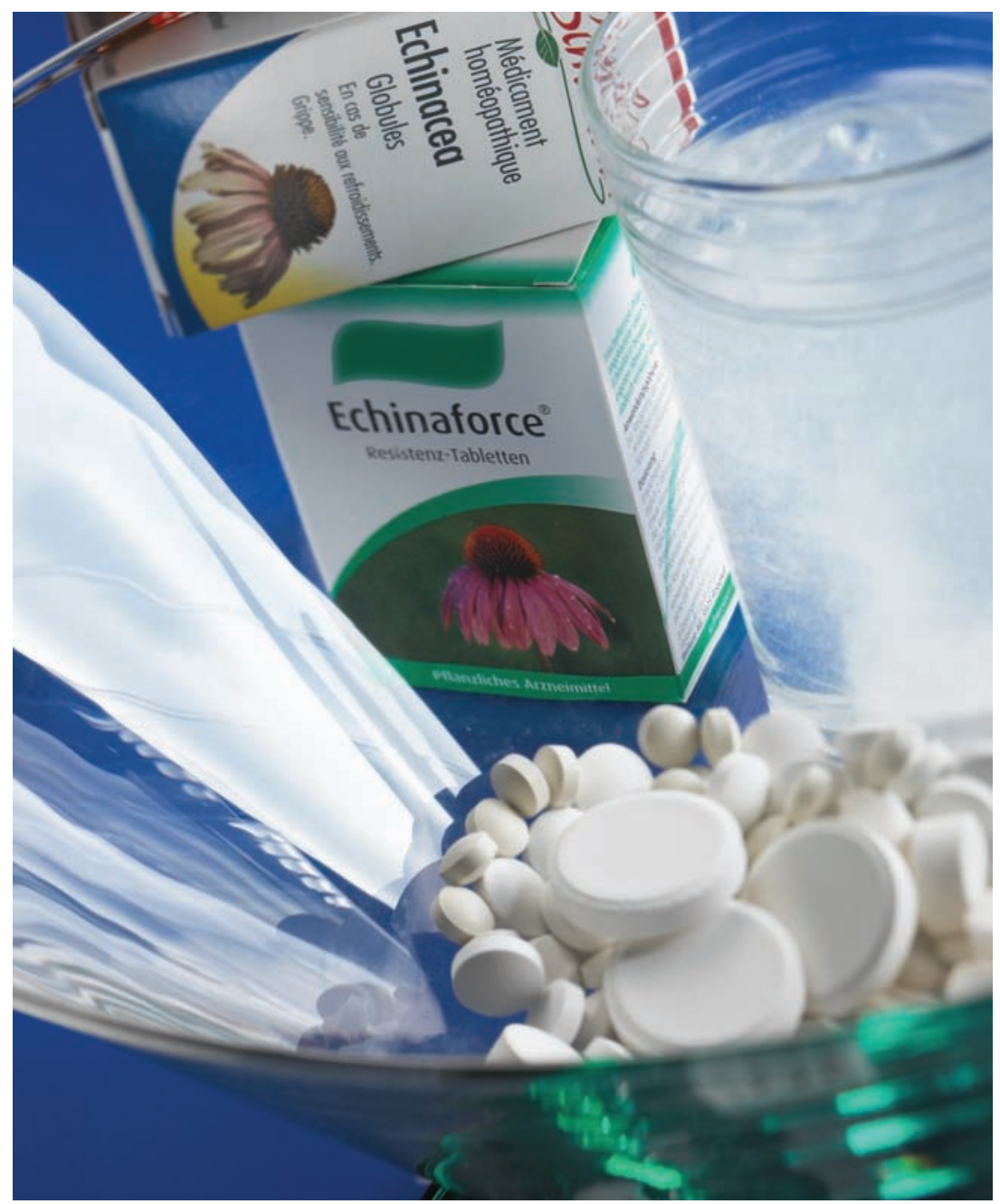

has been abandoned due to frequent nasal sideeffects. Macrolide antibiotics, bafilomycin A1 and erythromycin have been shown to inhibit ICAM-1 epithelial expression, and hypotheses about their potential as anti-inflammatory agents have yet to be definitively proved [42], as clinical proof is missing or negative.

During the last few years, anti-rhinoviral compounds such as plecoranil (Schering-Plough Corporation, Kenilworth, NJ, USA), which act by preventing the uncoating of picornaviruses [43], the RV $3 \mathrm{C}$ protease inhibitor ruprintrivir (Agouron Pharmaceuticals Inc., San Diego, CA, USA) [44] and soluble ICAM-1 (tremacarna/BIRR; Boehringer Ingelheim Pharmaceuticals Inc., Ridgefield, CT, USA) [45] have shown promising results in early-stage clinical trials, but have not yet reached the bedside.

Therefore, strategies for virus-induced asthma and related exacerbations are, in principal, anti-inflammatory, following strategies against persistent asthma. Glucocorticoids (GCs) are effective in vitro [46]; however, they show poor efficacy in models of human experimental infection [47]. In almost all major clinical studies, no virological identification during exacerbations has been performed. Therefore, it is not possible to conclude whether the benefit observed with GCs during exacerbations also includes virusinduced ones. This is also the case for GCs in combination with long-acting $\beta_{2}$-agonists (LABAs), which are superior to GCs alone in reducing the frequency of asthma exacerbations [48]. However, a recent study demonstrated that in vitro treatment with GCs/LABA was able to suppress the production of pro-inflammatory mediators in RV-infected bronchial epithelial cells in a synergistic or additive manner [49]. These data suggest the need for focused clinical studies looking into the combined effect of GCs/LABA in virus-induced asthma exacerbations.

Finally, there is evidence that leukotriene receptor antagonists may be effective in virusinduced asthma. BISCAARD et al. [50] used montelukast in the prevention of virus-induced asthma exacerbations in 2-5-year-old children taking part in a 12-month, multicentre, double-blind, parallel-group study. Children receiving montelukast had a $32 \%$ reduction in asthma exacerbations, a delayed time to first exacerbation and less use of inhaled GCs.

In conclusion, there are promising strategies for either specific antiviral or anti-inflammatory prevention/treatment of virus-induced asthma exacerbations. However, more focused clinical studies are needed in order to bring any of these approaches closer to clinical practice.

\section{Table 2 Proposed therapies against virus-induced asthma exacerbations}

\author{
Vitamin C \\ Zinc gluconate lozenges \\ $V L D L$ receptor fragments \\ Soluble ICAM derivatives \\ RV 3 C protease inhibitors \\ Pleconaril \\ IFN- $\alpha_{2}$ \\ IFN- $\beta$ \\ Inhaled GC therapy \\ GCs in combination with $\beta_{2}$-agonists \\ Bafilomycin A1 \\ Erytromycin \\ Inhibitors of NF- $\kappa B$ signalling
}

VLDL: very low-density lipoprotein; GC: glucocorticoid. 


\section{References}

1. Johnston SL, Pattemore PK, Sanderson G, et al. Community study of the role of viral infections in exacerbations of asthma. BMJ 1995; 310: 1225-1229.

2. Nicholson KG, Kent J, Ireland DC. Respiratory viruses and exacerbations of asthma in adults. BMJ 1993; 307: $982-986$.

3. Rakes GP, Arruda E, Ingram JM, et al. Rhinovirus and respiratory syncytial virus in wheezing children requiring emergency care. IgE and eosinophil analyses. Am J Respir Crit Care Med 1999; 159: 785-790.

4. Freymuth F, Vabret A, Brouard J, et al. Detection of viral, Chlamydia pneumoniae and Mycoplasma pneumoniae infections in exacerbations of asthma in children. J Clin Virol 1999; 13: 131-139.

5. Atmar RL, Guy E, Guntupalli KK, et al. Respiratory tract viral infections in inner-city asthmatic adults. Arch Intern Med 1998; 158: 2453-2459.

6. Wark PA, Johnston SL, Moric I, Simpson JL, Hensley MJ, Gibson PG. Neutrophil degranulation and cell lysis is associated with clinical severity in virus-induced asthma. Eur Respir J 2002; 19: 68-75.

7. Papadopoulos NG, Johnston SL. The role of viruses in the induction and progression of asthma. Curr Allergy Asthma Rep 2001; 1: 144-152.

8. Papadopoulos NG, Moustaki M, Tsolia M, et al. Association of rhinovirus infection with increased disease severity in acute bronchiolitis. Am J Respir Crit Care Med 2002; 165: 1285-1289.

9. Johnston SL. Overview of virus-induced airway disease. Proc Am Thorac Soc 2005; 2: 150-156.

10. Papadopoulos NG, Johnston SL. Rhinoviruses. In: Zuckerman AJ, ed. Principles and Practice of Clinical Virology. 5th Edn. Sussex, John Wiley \& Son, 2004.

11. Teichtahl H, Buckmaster N, Pertnikovs $E$. The incidence of respiratory tract infection in adults requiring hospitalization for asthma. Chest 1997; 112: 591-596.

12. Williams JV, Crowe JE Jr, Enriquez R, et al. Human metapneumovirus infection plays an etiologic role in acute asthma exacerbations requiring hospitalization in adults. J Infect Dis 2005; 192: 1149-1153.

13. Xepapadaki P, Psarras S, Bossios A. Human Metapneumovirus as a causative agent of acute bronchiolitis in infants. $J$ Clin Virol 2004; 30: 267-270.

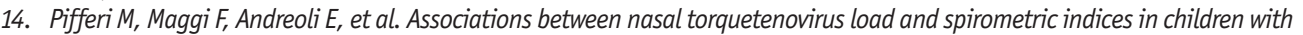
asthma. J Infect Dis 2005; 192: 1141-1148.

15. Papadopoulos NG, Sanderson G, Hunter J, Johnston SL. Rhinoviruses replicate effectively at lower airway temperatures. J Med Virol 1999; 58: 100-104.

16. Papadopoulos NG, Bates PJ, Bardin PG, et al. Rhinoviruses infect the lower airways. J Infect Dis 2000; 181: $1875-1884$.

17. Mosser AG, Vrtis R, Burchell L. Quantitative and qualitative analysis of rhinovirus infection in bronchial tissues. Am J Respir Crit Care Med 2005; 171: 645-651.

18. Gern JE, Vrtis R, Grindle KA, Swenson C, Busse WW. Relationship of upper and lower airway cytokines to outcome of experimental rhinovirus infection. Am J Respir Crit Care Med 2000; 162: 2226-2231.

19. Donninger H, Glashoff R, Haitchi HM, et al. Rhinovirus induction of the CXC chemokine epithelial-neutrophil activating peptide-78 in bronchial epithelium. J Infect Dis 2003; 187: 1809-1817.

20. Psarras S. Rhinovirus infection stimulates production of fibroblast growth factor-2 by airway epithelial and stromal cells. Allergy 2002; 57: Suppl. 73, 296.

21. Uhl EW, Castleman WL, Sorkness RL, Busse WW, Lemanske RFJr, McAllister PK. Parainfluenza virus-induced persistence of airway inflammation, fibrosis, and dysfunction associated with TGF-beta 1 expression in brown Norway rats. Am J Respir Crit Care Med 1996; 154: 1834-1842.

22. Julkunen I. Inflammatory responses in influenza A virus infection. Vaccine 2000; 19: Suppl. 1, S32.

23. Papi A, Johnston SL. Rhinovirus infection induces expression of its own receptor intercellular adhesion molecule 1 (ICAM-1) via increased NF- KB-mediated transcription. J Biol Chem 1999; 274: 9707-9720.

24. Bossios A, Psarras S, Gourgiotis D, et al. Rhinovirus infection induces cytotoxicity and delays wound healing in bronchial epithelial cells. Respir Res 2005; 6: 114.

25. Deszcz L, Gaudernak E, Kuechler E, Seipelt J. Apoptotic events induced by human rhinovirus infection. J Gen Virol 2005; 86: 1379-1389.

26. Wark PAB. Asthmatic bronchial epithelial cells have a deficient innate immune response to infection with rhinovirus. J Exp Med 2005; 201: 937-947.

27. Bryne GI, Ojcius DM. Chlamydia and apoptosis: life and death decisions of an intracellular pathogen. Nat Rev Microbiol 2004; 2: 802-808.

28. Johnston SL, Martin RJ. Chlamydia pneumoniae and Mycoplasma pneumoniae: a role in asthma pathogenesis? Am J Respir Crit Care Med 2005; 172: 1078-1089.

29. Papadopoulos NG, Stanciu LA, Papi A, Holgate ST, Johnston SL. A defective type 1 response to rhinovirus in atopic asthma. Thorax 2002; 57: 328-332.

30. Xatzipsalti M, Kyrana S, Tsolia M, et al. Rhinovirus viremia in children with respiratory infections. Am J Respir Crit Care Med 2005; 172: 1037-1040.

31. Fraenkel DJ, Bardin PG, Sanderson G, Lampe F, Johnston SL, Holgate ST. Lower airways inflammation during rhinovirus colds in normal and in asthmatic subjects. Am J Respir Crit Care Med 1995; 151: 879-886.

32. Papadopoulos NG, Stanciu LA, Papi A, Holgate ST, Johnston SL. Rhinovirus-induced alterations on peripheral blood mononuclear cell phenotype and costimulatory molecule expression in normal and atopic asthmatic subjects. Clin Exp Allergy 2002; 32: 537-542.

33. Bossios A, Xapzitsalti M, Manoussakis E, Psarros F, Saxoni-Papageorgiou P, Papadopoulos NG. Expression of costimulatory molecules in peripheral blood mononuclear cells of atopic asthmatic children during virus-induced asthma exacerbations. Int Arch Allergy Immunol 2004; 134: 223-226.

34. Gern JE, Calhoun W, Swenson C, Shen G, Busse WW. Rhinovirus infection preferentially increases lower airway responsiveness in allergic subjects. Am J Respir Crit Care Med 1997; 155: 1872-1876.

35. Xepapadaki P, Papadopoulos NG, Bossios A, Manoussakis E, Manousakas T, Saxoni-Papageorgiou P. Duration of postviral airway hyperresponsiveness in children with asthma: effect of atopy. J Allergy Clin Immunol 2005; 116: 299-304.

36. Green RM, Custovic A, Sanderson G, Hunter J, Johnston SL, Woodcock A. Synergism between allergens and viruses and risk of hospital admission with asthma: case-control study. BMJ 2002; 324: 763.

37. Calhoun WJ, Dick EC, Schwartz LB, Busse WW. A common cold virus, rhinovirus 16, potentiates airway inflammation after segmental antigen bronchoprovocation in allergic subjects. J Clin Invest 1994; 94: 2200-2208.

38. de Kluïver J, Evertse CE, Sont JK, et al. Are rhinovirus-induced airway responses in asthma aggravated by chronic allergen exposure? Am J Respir Crit Care Med 2003; 168: 1174-1180. 


\section{Suggested answers}

1. $b$

2. $b, e, a, d, c$

3

a) False.

b) False.

c) True.
39. Chauhan AJ, Inskip HM, Linaker $\mathrm{CH}$, et al. Personal exposure to nitrogen dioxide $\left(\mathrm{NO}_{2}\right)$ and the severity of virus-induced asthma in children. Lancet 2003; 361: 1939-1944.

40. Spannhake EW, Reddy SP, Jacoby DB, YU XY, Saatian B, Tian J. Synergism between rhinovirus infection and oxidant pollutant exposure enhances airway epithelial cell cytokine production. Environ Health Perspect 2002; 110: 665-670.

41. Yamaya M, Sasaki H. Rhinovirus and asthma. Viral Immunol 2003; 16: 99-109.

42. Suzuki T, Yamaya M, Sekizawa K, et al. Erythromycin inhibits rhinovirus infection in cultured human tracheal epithelial cells. Am J Respir Crit Care Med 2002; 165: 1113-1118.

43. Ledford RM, Patel NR, Demenczuk TM, et al. VP1 sequencing of all human rhinovirus serotypes: insights into genus phylogeny and susceptibility to antiviral capsid-binding compounds. J Virol 2004; 78: 3663-3674.

44. Hayden FG, Turner RB, Gwaltney JM, et al. Phase II, randomized, double-blind, placebo-controlled studies of ruprintrivir nasal spray 2-percent suspension for prevention and treatment of experimentally induced rhinovirus colds in healthy volunteers. Antimicrob Agents Chemother 2003; 47: 3907-3916.

45. Turner RB, Wecker MT, Pohl G, et al. Efficacy of tremacamra, a soluble intercellular adhesion molecule 1, for experimental rhinovirus infection: a randomized clinical trial. JAMA 1999; 281: 1797-1804.

46. Papi A, Papadopoulos NG, Degitz K, Holgate ST, Johnston SL. Corticosteroids inhibit rhinovirus-induced intercellular adhesion molecule-1 up-regulation and promoter activation on respiratory epithelial cells. J Allergy Clin Immunol 2000; 105: 318-326.

47. Grunberg K, Sharon RF, Sont JK, et al. Rhinovirus-induced airway inflammation in asthma: effect of treatment with inhaled corticosteroids before and during experimental infection. Am J Respir Crit Care Med 2001; 164: 1816-1822.

48. O'Byrne PM, Bisgaard H, Godard PP, et al. Budesonide/formoterol combination therapy as both maintenance and reliever medication in asthma. Am J Respir Crit Care Med 2005; 171: 129-136.

49. Edwards MR, Johnson MW, Johnston SL. Combination therapy: synergistic suppression of virus-induced chemokines in airway epithelial cells. Am J Respir Cell Mol Biol 2006; 34: 616-624.

50. Bisgaard H, Zielen S, Garcia-Garcia ML, et al. Montelukast reduces asthma exacerbations in 2- to 5- year old children with intermittent asthma. Am J Respir Crit Care Med 2005; 171: 315-322. 